\title{
Helen Salisbury: Evidence and experience
}

\author{
Helen Salisbury GP \\ Oxford
}

Most doctors would like to think that they practise evidence based medicine, but it's difficult to avoid being biased by our own experience.

In 2014 the National Institute for Health and Care Excellence (NICE) published guidance for primary prevention of cardiovascular disease. ${ }^{1}$ It suggested that we should offer lipid modification therapy (in other words, statins) to patients with a QRISK2 score greater than $10 \%$. This is equivalent to an estimated risk of having a stroke or heart attack of more than one in 10 over the next 10 years.

At an update meeting I attended a few months later, the audience of about 150 GPs was asked whether we were offering statins accordingly to most of our older patients. Some doctors raised their hand, but certainly less than half. The next question was more revealing: how many of us would take a statin if our QRISK2 score was just over 10\%? Very few hands stayed in the air.

I repeated this story to a cardiologist, who opined that there would be no point in asking a group of his colleagues, as they were all taking statins already.

I have no way of knowing whether that's true, but it occurred to me that, although both groups of professionals have access to the same evidence, we have very different experiences of patients. In a GP surgery we hear many complaints of aching muscles and disturbed sleep that patients attribute to their statins. What we don't see, by definition, are the heart attacks prevented. By contrast, cardiologists spend much of their professional lives treating patients with clogged-up coronary arteries who might have avoided this condition if they'd taken a statin sooner.
We need to be aware of our biases. I know that I'm sceptical about extending statin use and about the increasing medicalisation of older people just because their age puts them at risk. I also need to guard against letting my own personal dislike of taking medicines creep into the consultation. My discussions with patients about cardiovascular risk have evolved to focus on physical activity, weight, and smoking. QRISK and statins get a mention, and I try hard to summarise the evidence, including the numbers needed to treat to avoid an adverse outcome.

As scientists we're all empiricists, basing our beliefs on observations. However, when the evidence is conflicting, sometimes what we've experienced ourselves, or what we've seen our patients experience, carries more weight than a meta-analysis we read last week. One unexpected diagnosis can skew our investigations and referrals for months, even though the likelihood of it turning up again hasn't increased. These reactions are normal and probably unavoidable, which is why self scrutiny-asking "what could be affecting my decisions?"-is so essential.

Competing interests: See www.bmj.com/about-bmj/freelance-contributors. Provenance and peer review: Commissioned; not externally peer reviewed.

1 National Institute for Health and Care Excellence. Cardiovascular disease: risk assessment and reduction, including lipid modification. Clinical guideline [CG181]. Jul 2014. https:// www.nice.org.uk/guidance/cg181/chapter/1-Recommendations.

Published by the BMJ Publishing Group Limited. For permission to use (where not already granted under a licence) please go to http://group.bmj.com/group/rights-licensing/ permissions 